\title{
STATUS QUO AND FUTURE DIRECTIONS OF FACILITY MANAGEMENT: A BIBLIOMETRIC-QUALITATIVE ANALYSIS
}

\author{
Yongkui $\mathrm{LI}^{1}$, Yan $\mathrm{ZHANG}^{1}$, Jianjun WEI ${ }^{1,2}$, Yilong $\mathrm{HAN}^{1,{ }^{*}}$ \\ ${ }^{1}$ School of Economics and Management, Tongji University, Shanghai, China \\ ${ }^{2}$ Shanghai Shenkang Hospital Development Centre, Shanghai, China
}

Received 28 December 2018; accepted 02 April 2019

\begin{abstract}
Facility management (FM) has received extensive attention from practitioners and researchers. While FM is continuously maturing as a scientific discipline and relevant studies are constantly growing, there are no holistic reviews of current research. The information in previous studies is generally scattered, and existing literature reviews mostly focused on specific aspects of FM. It is necessary for researchers and practitioners to obtain a thorough view of the current status in the FM field and future development trends that have been summarized and discussed in depth. Using a bibliometricqualitative analysis, a total of 724 academic journal papers on FM, between 1995 and 2018, were reviewed. A number of the latest advancements and emergent trends were identified based on knowledge maps in FM, including changing circumstances, enhancing information technology, all-around facility manager, strategic performance management, sustainable FM and innovative FM practice. It is hoped that this review can help researchers understand the current body of FM knowledge. The future directions were also highlighted in this study to help researchers identify areas where research is most needed. This study could also help practitioners to address upcoming challenges in the FM field.
\end{abstract}

Keywords: facility management, bibliometric-qualitative analysis, visual mapping, changing circumstances, facility manager, performance management.

\section{Introduction}

Due to the globalization, the development of information technology, and the higher demand for the quality of life, the efforts to manage properties and/or facilities in the built environment have become increasingly prominent to improve efficiency as well as meet social needs. In fact, operation and maintenance is the most costly phase of a facility's life-cycle (Jordani, 2010; Parsanezhad \& Dimyadi, 2014). A study from the National Institute of Standards and Technology (NIST) demonstrated that two-thirds of the estimated lost in the USA capital facilities industry is due to inefficiencies during operations and maintenance phase (Rundell, 2006). As a key business function of organizations, facility management (FM) not only affects the income and cost of organizations but also affects the brand and social image. At the same time, FM plays an increasingly important role in the production or service of the core business, the quality of life of employees, health and safety, and the working environment (Ventovuori, Lehtonen, Salonen, \& Nenonen, 2007). FM practice also contributes $5-10 \%$ of the GDP in developed countries
(Aziz, Nawawi, \& Ariff, 2016). The founding of many professional FM institutions around the world (e.g., IFMA in the US, BIFM in the UK, GEFMA in Germany, JFMA in Japan, and FMAA in Australia) is also an indication of the increasing importance of FM.

The definition and scope of FM varies from country to country due to a number of major factors, such as geographical locations, building and facility characteristics, business environment, and external interventions (Pärn, Edwards, \& Sing, 2017). Focusing on the workplace efficiency, the concept of FM today can be traced back to the 1980s when the railway companies in the US initiated the idea of providing facilities-related services (White, Moseki, Tembo, \& Cloete, 2011). On contrary, the FM in Europe, especially in the UK, has been paid more attention on health and productivity, integrated services and improvement of the working environment rather than technology (Maliene, Alexander, \& Lepkova, 2008). The application of FM was further extended to many other building sectors, including healthcare, education, office, public buildings and airport, etc.

${ }^{*}$ Corresponding author. E-mail: yilong.han@tongji.edu.cn 
From the technological perspective, Aziz et al. (2016) described how FM technologies evolved, from the initial email communications to the most advanced techniques, such as Building Information Modeling (BIM) and Radio Frequency Identification (RFID). Integrated solutions with different technologies helped accelerate the relatively slow technology diffusion process in the field of FM (Mignard \& Nicolle, 2014; Ahmed, Tezel, Aziz, \& Sibley, 2017). It is worth pointing out that technology solutions are often applied to support information management in FM, rather than asset management and maintenance. In fact, the main reason behind changes in the field of FM is the increasing economic pressure on building operations and facilities maintenance (Shohet \& Lavy, 2004, 2017). Facility managers are accountable for directing the efforts on managing building operations to increase the capability and efficiency within an organization, while the "customers" in FM and their satisfaction measurements as a generic strategic tool were not sufficiently researched (Pilanawithana \& Sandanayake, 2017). The application of performance measurement has been embraced in FM through in-depth analysis (Enoma \& Allen, 2007). In addition, most recently, sustainable facility management has become one of the primary research themes in the field of FM (Nielsen, Sarasoja, \& Galamba, 2016).

Although FM research has been developed over the last decades, the information gathered was relatively scattered and the topics were generally independently discussed. We are lacking a holistic understanding of current FM research status for both academics and practitioners. Some scholars initiated review efforts on the topic of FM, but their research focuses were limited to certain aspects of the broad FM field. Stressing on research methodology, Ventovuori et al. (2007), in his review paper, pointed out that the FM discipline must increasingly use the testing of hypotheses and more robust data analysis techniques in order to be recognized as a stand-alone discipline. Ebbesen and Bonke (2014) reviewed 112 papers published during 2008-2013, and found that the current FM research related to IT represented an unbalanced focus on some specific technologies and processes. Wong, Ge, and $\mathrm{He}$ (2018) reviewed and summarized applications of various major digital technologies in FM, such as BIM, reality capture technology, Internet of Things (IoT), and Geographic Information System (GIS). However, none of those contributed to a systematic and thorough overview of the current research status in the field of FM, nor do they provided the newest insights for future development. As the industry and research interests increase, a comprehensive summary of the FM research and a higher level of critical thinking about future directions must be conducted. To fill this gap, our study in this paper attempts 1) to recap how FM research evolves from 1995 to 2018, 2) to have a holistic understanding of current FM research status, and 3) to identify emerging trends for future FM exploration.
The rest of this paper is organized as follows. Section 1 presents the research methodology that was used in this study. Section 2 demonstrates the results of the analysis, including aggregate analysis, keyword co-occurrence analysis, and keyword cluster analysis. In Section 3, six potential research directions of FM are discussed comprehensively integrating our bibliometric analysis and a systematic literature review. In the end, we conclude the theoretical and practical findings of this study.

\section{Research methodology}

In this research, we adopted a mixed-method literature review approach that synthesizes both quantitative and qualitative methods. Bibliometric, as a quantitative approach, offered analytical measurements and data visualization techniques for a better understanding of the dataset. On the other hand, the qualitative analysis could reveal the analysis and classification of different concepts, themes, and theories from the carefully selected studies, and integrating the results of quantitative analysis.

\subsection{Retrieval and screening of papers}

The Web of Science (WoS) core database was our primary data collection resource. In addition, two important journals in the FM field outside of the WoS core database, namely Facilities and Journal of Facility Management, were included for a holistic and systematic analysis. The query used in this study was "facilit* management" in the Title/Abstract/Keywords. Since we found that most FM-related publications were published after the year 1995, we set the timespan for the relevant publications search as "1995-2018" (ended on December 31, 2018). All publications were retrieved on Jan 4th, 2019. We performed exclusion criteria that only include English journal publications for analytical purposed. Book reviews, editorials, conference papers and call for paper information, as well as duplicated papers were excluded. A total of 1272 publications were identified. Further, the following two steps of screening were conducted to select the publications that met our intended research purpose. First, the authors carefully and separately screened and examined the publications by title and abstract. Since apparently irrelevant papers should be excluded by assessing whether they directly analyse FM topics. Second, the controversial publications were re-examined through the full text. In the end, a total of 724 publications were identified for the further analysis.

\subsection{Bibliometric analysis}

A field of knowledge is generally represented by bibliographic records of related publications. Similarly, FM publications would provide insightful evidences of developments in this field, leading to an influential driver for FM development. Because of extensive research topics and achievements in the field of FM, bibliometric techniques 
are more suitable as opposed to manual literature analysis process to obtain a comprehensive viewpoint of research patterns and tendencies (Pollack \& Adler, 2015). In this study, we use the CiteSpace software to perform co-occurrence analysis, and to visualize the bibliometric networks and research clusters.

Keyword co-occurrence analysis and the keyword cluster analysis could help identify research status and trends. Keyword co-occurrence analysis would give a primary representation of the field of FM. Its principle is to count the number of times keywords appear in the same group of documents and to measure the closeness between them based on the number of co-occurrences (Chen, 2006). Cluster analysis is a mathematical and statistical method for identifying the potential semantic themes in textual data (Hossain, Prybutok, \& Evangelopoulos, 2011). Based on the co-occurrence network, a knowledge cluster is then created by the spectral clustering algorithm, and the labelled words are extracted from the relevant literature in order to characterize the research directions and frontiers (Yalcinkaya \& Singh, 2015; Li \& Chen, 2016). Algorithms for extracting labelled words include log-likelihood rate (LLR), frequency-inverse document frequency ( $\left.\mathrm{tf}^{*} \mathrm{idf}\right)$, and mutual information (MI) (Chen, 2014). Modularity $\mathrm{Q}$ and Mean Silhouette scores are two significant indexes that evaluate the quality of overall clustering networks. Modularity $\mathrm{Q}$ is the index of network modularization, while Mean Silhouette is the index to measure the network homogeneity.

\section{Results and findings}

\subsection{Aggregate analysis}

Based on the results of literature retrieval and screening, Figure 1 shows the number of FM publications per year from 1995 to 2018. The analysis of the texts that were published each year provides an indication of attention that research in the FM field has received. Since 1995, the number of publications on FM remained relatively stable, averaging about 15 per year. After 2010, the number of publications began to increase, doubling from the previ- ous years. By 2015, the number doubled again. There are indications that the academic community is showing an increasing tendency to publish articles about FM in the future. In addition, this upward trend is not due to the general increase in publications, as the number of annual publications in the most journals related to FM is relatively stable. On the one hand, taking International Journal of Strategic Property Management as an example, the number of annual publications in the journal has been particularly stable in the last decade, with only $2-5$ publications growing year by year. On the other hand, according to the results of statistical and polynomial regression analysis, in the past decade, the proportion of FM-related publications in all of the publications of the six related journals (Facilities, Journal of Facility Management, Automation in Construction, Journal of Performance of Constructed, Building Research and Information, and International Journal of Strategic Property Management) has been increasing.

The distribution of journals provides an indication of the core journals in the research field, and it also provides guidance for scholars to choose the platforms that can be used to publish their work and acquire knowledge about FM. According to the statistical results, 724 publications were published in 166 journals, and, initially, it appeared to be relatively scattered. However, there were 544 publications in the top 20 journals, which was more than $75 \%$ of the total FM-related publications, indicating that a group of core journals had recognized the importance of FM research. Table 1 lists the top 10 journals and their impact factor that had published at least seven publications related to FM. The two most important journals in terms of the number of their publications in the FM field are Facilities and Journal of Facility Management. The number of FM publications in these two journals far exceeds those in other journals, which is also why we include the search results of these two journals in the data collection and paper screening process. Considering the impact factor and CiteScore from Scopus of journals, at present, FMrelated journals are not sufficiently influential, and the FM research field lacks high-impact representative journals. There are six journals with impact factor larger than 1.0 in

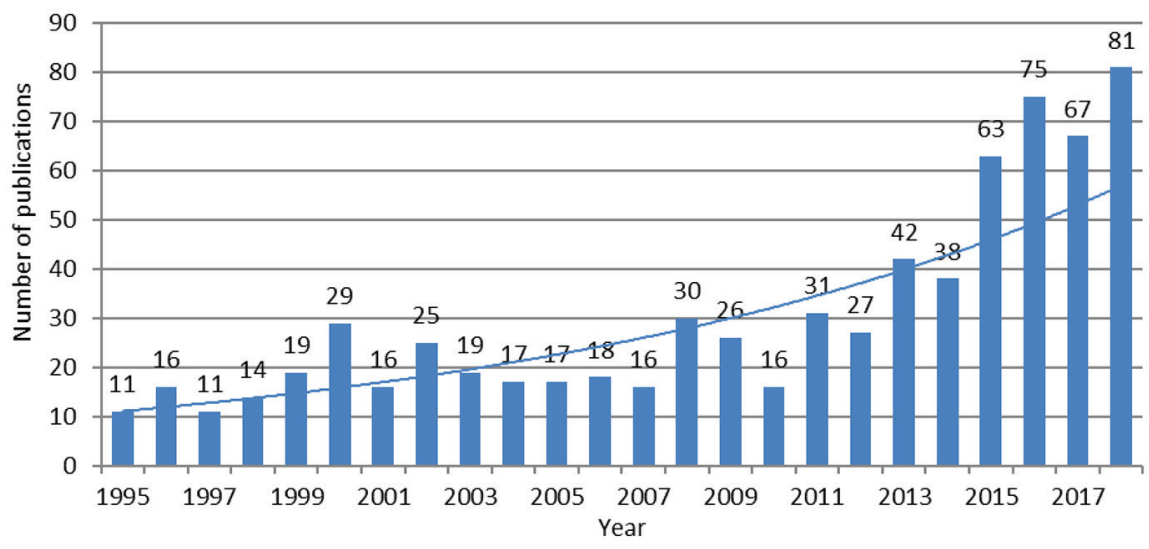

Figure 1. Number of FM publications per year from 1995 to 2018 
the top 10 journals, but there are few FM-related publications in the six journals. Fortunately, most of the FM-related publications in the six journals were published in the past five years, which is a good trend for the development of FM research. In addition, only 60 of 724 publications are open access texts.

Frequency of citations can be used to identify publications with high applicable value and academic influence in a given subject area, and the content can be measured and interpreted to determine the mainstream research and its research level in the field, and this, in turn, can be used to provide directions for future research. According to the citation indices in Google Scholar (collected by March 12, 2019), we determined the top 10 most-cited publications, as shown in Table 2. Most of them were published more than 10 years ago, and the impact of the top three highlycited papers are prominent, with significantly more citations compared to other papers on the list.

Table 1. Top-10 journals with impact factor and CiteScore

\begin{tabular}{|c|c|c|c|c|}
\hline No. & Journal & Publications & Impact factor & CiteScore \\
\hline 1 & Facilities & 305 & - & 1.50 \\
\hline 2 & Journal of Facilities Management & 90 & - & 1.34 \\
\hline 3 & Automation in Construction & 27 & 4.032 & 5.36 \\
\hline 4 & Journal of Performance of Constructed Facilities & 17 & 1.197 & 1.35 \\
\hline 5 & Building Research and Information & 13 & 3.468 & 2.97 \\
\hline 6 & International Journal of Strategic Property Management & 10 & 1.571 & 1.61 \\
\hline 7 & Journal of Computing in Civil Engineering & 10 & 1.798 & 2.07 \\
\hline 8 & Built Environment Project and Asset Management & 9 & - & 1.41 \\
\hline 9 & Advanced Engineering Informatics & 8 & 3.358 & 4.15 \\
\hline 10 & Journal of Information Technology in Construction & 7 & - & 1.73 \\
\hline
\end{tabular}

Table 2. Top-10 publications with the most citations

\begin{tabular}{|c|c|c|c|c|c|}
\hline No. & Titles of texts & Publication name & Year & Authors & Citations \\
\hline 1 & $\begin{array}{l}\text { Moving from performance } \\
\text { measurement to performance } \\
\text { management }\end{array}$ & Facilities & 2002 & $\begin{array}{l}\text { Dilanthi Amaratunga, } \\
\text { David Baldry }\end{array}$ & 451 \\
\hline 2 & $\begin{array}{l}\text { Application areas and data } \\
\text { requirements for BIM-enabled facilities } \\
\text { management }\end{array}$ & $\begin{array}{l}\text { Journal of Construction } \\
\text { Engineering and } \\
\text { Management }\end{array}$ & 2012 & $\begin{array}{l}\text { Burcin Becerik-Gerber, } \\
\text { Farrokh Jazizadeh, } \\
\text { Nan Li, } \\
\text { Gulben Calis }\end{array}$ & 444 \\
\hline 3 & $\begin{array}{l}\text { Green buildings, organizational success } \\
\text { and occupant productivity }\end{array}$ & $\begin{array}{l}\text { Building Research \& } \\
\text { Information }\end{array}$ & 2000 & Judith Heerwagen & 356 \\
\hline 4 & $\begin{array}{l}\text { Green strategy for gaining competitive } \\
\text { advantage in housing development: a } \\
\text { China study }\end{array}$ & $\begin{array}{l}\text { Journal of Cleaner } \\
\text { Production }\end{array}$ & 2011 & $\begin{array}{l}\text { Xiaoling Zhang, } \\
\text { Liyin Shen, } \\
\text { Yuzhe Wu }\end{array}$ & 210 \\
\hline 5 & $\begin{array}{l}\text { Facilities management: A “Jack of all } \\
\text { trades"? }\end{array}$ & Facilities & 2001 & $\begin{array}{c}\text { Linda Tay, } \\
\text { Joseph T.L. Ooi }\end{array}$ & 174 \\
\hline 6 & $\begin{array}{l}\text { Tracking components and maintenance } \\
\text { history within a facility utilizing radio } \\
\text { frequency identification technology }\end{array}$ & $\begin{array}{l}\text { Journal of Computing in } \\
\text { Civil Engineering }\end{array}$ & 2007 & $\begin{array}{l}\text { Esin Ergen, } \\
\text { Burcu Akinci, } \\
\text { Bill East, } \\
\text { Jeff Kirby }\end{array}$ & 162 \\
\hline 7 & $\begin{array}{l}\text { Four competing futures for facility } \\
\text { management }\end{array}$ & Facilities & 2013 & Bev Nutt & 169 \\
\hline 8 & $\begin{array}{l}\text { An integrated resource management } \\
\text { view of facilities management }\end{array}$ & Facilities & 1999 & Danny Shiem-Shin Then & 159 \\
\hline 9 & $\begin{array}{l}\text { Building performance and its relevance } \\
\text { to facilities management }\end{array}$ & Facilities & 1996 & James Douglas & 155 \\
\hline 10 & $\begin{array}{l}\text { The creation of a management-by- } \\
\text { variance tool for facilities management } \\
\text { performance assessment }\end{array}$ & Facilities & 1999 & $\begin{array}{l}\text { John Hinks, } \\
\text { Peter McNay }\end{array}$ & 143 \\
\hline
\end{tabular}




\subsection{The keyword co-occurrence analysis}

The detailed information of the journal publications was then imported in to CiteSpace for further analysis. Keyword co-occurrence networks embody the development of FM over time and displays important themes of the field. Figure 2 shows the overall keyword co-occurrence network. Different nodes in the map represent identified keywords that were used to summarize the nature and core of each publication. Links between nodes express relationships of co-occurrence, meaning two different keywords are used together in the same publication. The color of nodes and lines represents different years, and the size of the nodes shows the frequency of keyword co-occurrence.

Figure 2 shows the keywords that occurred most frequently. First, the frequency of "facility management" was the highest, which was determined by the theme of this study. Other keywords that related to "facility management" also included "facility" and "management". Similarly, by sorting the frequency of the usage of the keywords, we identified the keywords with higher frequencies, e.g., "BIM", "performance", "outsourcing", "sustainability", and "benchmarking". The keyword co-occurrence network is a static depiction of research themes of FM field which does not considered dynamic changes of terms over time. A time zone perspective can characterize this change, and the identified keywords are arranged in chronological order to show the interactive relationship. Figure 3 shows the evolution of keywords from 1995 to 2018. The lines between nodes represent co-occurrence links for different keywords. The color of these lines characterizes the time when a connection has been made for the first time.

Figure 3 contains 329 nodes, and the sizes of the nodes represent the frequencies of the keywords. The figure clearly shows the trends and processes of keywords over time in the field of FM. The history of FM research can be roughly divided into three phases, i.e., (1) 1995-2000, during which the top keywords were "facility management", "property management", "maintenance", "outsourcing", and "benchmarking", which are focused on how to promote the mature and vigorous development of FM; (2) 2001-2005, during which "performance", "environment", and "knowledge management" became the focus in the field of FM

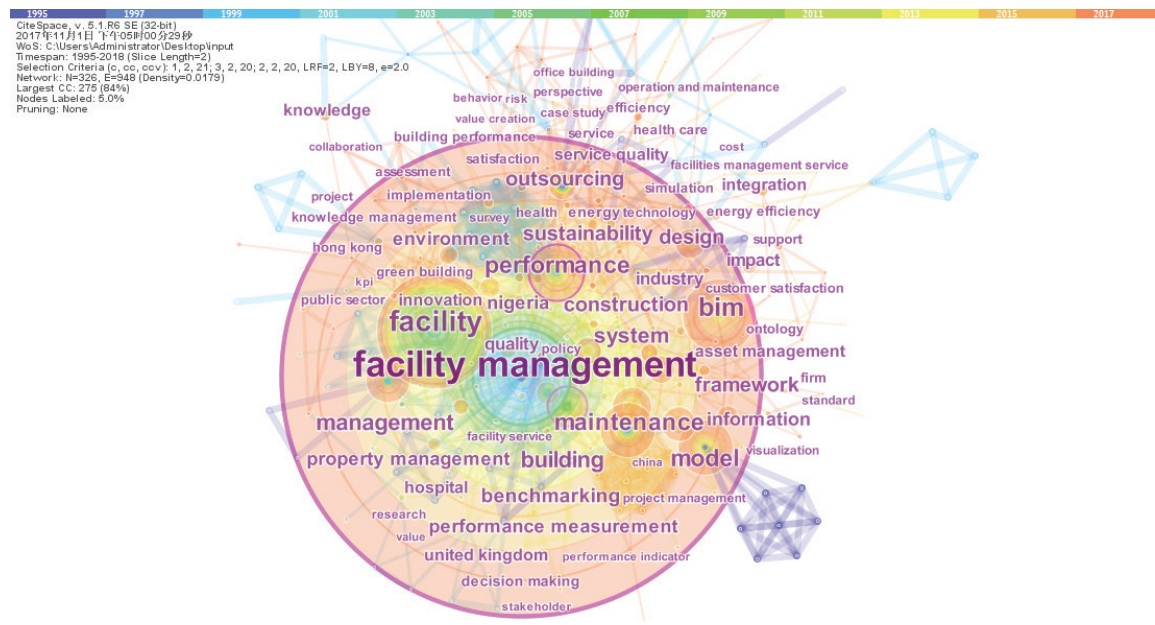

Figure 2. Keyword co-occurrence network of FM: 1995-2018

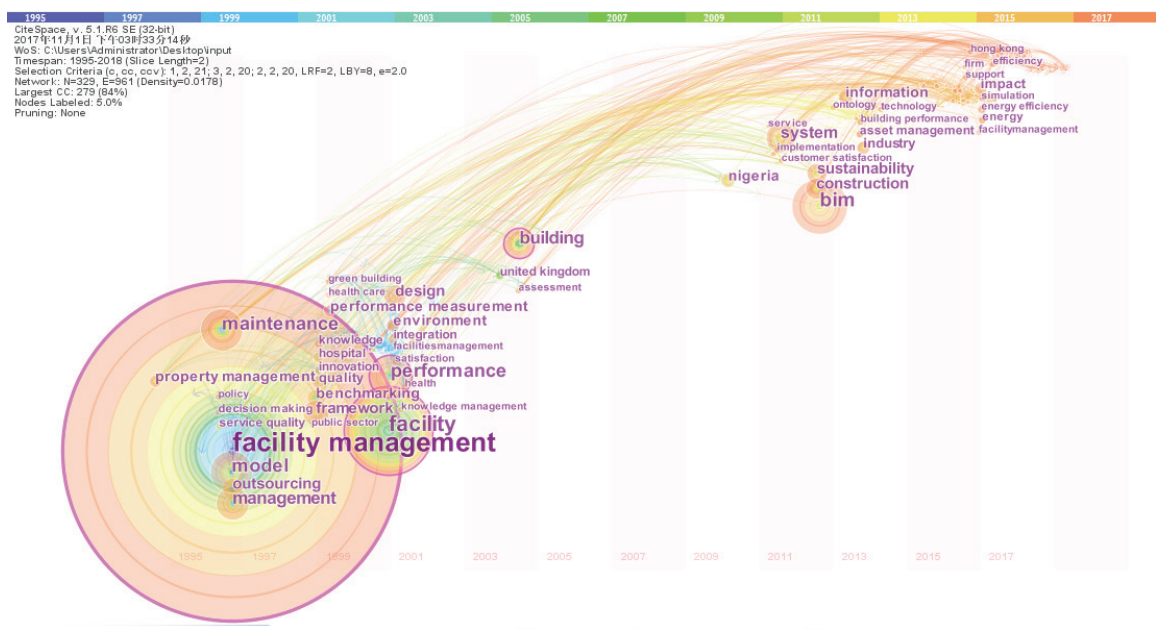

Figure 3. Time-zone view of the keyword co-occurrence network 
research; (3) 2011-2018, during which "BIM", "information", and "sustainability" became the focus in the field of FM research; these terms emphasize the importance of choosing suitable information technology (such as BIM) to deal with the changing circumstances and finally to fulfil the green and sustainable development of the FM field. In addition, the advent of the era of big data has taken FM research into a new stage. The integration of FM information is becoming more important in the context of big data, and FM is increasingly becoming concerned about the importance of collaboration, which is emerging as a frontier in FM research.

\subsection{The keyword cluster analysis}

The keyword co-occurrence network and the time zone perspective provide general insights regarding the FM field. However, they fail to clarify some of the main areas and structures of FM research. This study use cluster analysis to show prominent groups of themes and potential directions in the FM field. Each cluster represents a group of closely related keywords, and the clusters are sorted by how many keywords they explain. CiteSpace can automatically extract cluster labels from keywords based on a set of algorithms, and to some extent, the influence of the subjectivity of the analyst on the bibliometric analysis results can be avoided (Chen, Zhao, \& Xu, 2012).

Table 3 lists the characteristics of the cluster analysis and Figure 4 shows the result of cluster analysis in the FM field. The value of Modularity Q, 0.6922, is relatively high, indicating that the network is divided into loosely-coupled clusters (Newman, 2006). The Mean Silhouette score of 0.6919 reveals relatively high homogeneity of these clusters so that the network clusters are efficient and reliable
(Kaufman \& Rousseeuw, 2009). The clusters are numbered in a descending order based on the sizes of the clusters, starting from the largest cluster \#0, the second largest \#1, and so on.

Overall, the FM field has 12 prominent research clusters, namely, "facilities management issue", "life-cycle facility management", "measuring perception", "life cycle", "green maintainability framework", "green building", "managing change", "facilities maintenance", "useful tool", "facility manager", "tool handling system management", and "thirdwave Internet". Each of these clusters can be regarded as a research topic, and since multiple words may have the same meaning in some case, these research themes may partially overlap.

\section{Discussion: towards future FM directions}

After an in-depth examination of the 12 prominent research clusters that were identified through the bibliometric analysis, it can be found that some clusters have certain similarities and could be integrated to better demonstrate the overall structure, theme-divisions, and emerging trends in the FM field. "Managing change (\#6)" is regarded as the changing circumstances that promote the mature and vigorous development of the FM sector. "Useful tool (\#8)", "Tool handling system management (\#10)", and "Third-wave Internet (\#12)" cover the issues that focus on the influence and application of technology during the FM process, especially Information Technology (IT) (Lavikka, Lehtinen, \& Hall, 2017; Nielsen et al., 2016). "Life-cycle facility management (\#1)", "Life cycle (\#3)", and "Facility manager (\#9)" can be associated as all-round facility manager that in charge of the operation and maintenance of a building's lifecycle (Pilanawithana

Table 3. Overall characteristics of the cluster analysis

\begin{tabular}{|c|c|c|c|c|c|}
\hline Network & Nodes & Edges & Density & Modularity Q & Mean Silhouette \\
\hline Keyword co-occurrence & 331 & 968 & 0.0177 & 0.6922 & 0.6919 \\
\hline
\end{tabular}

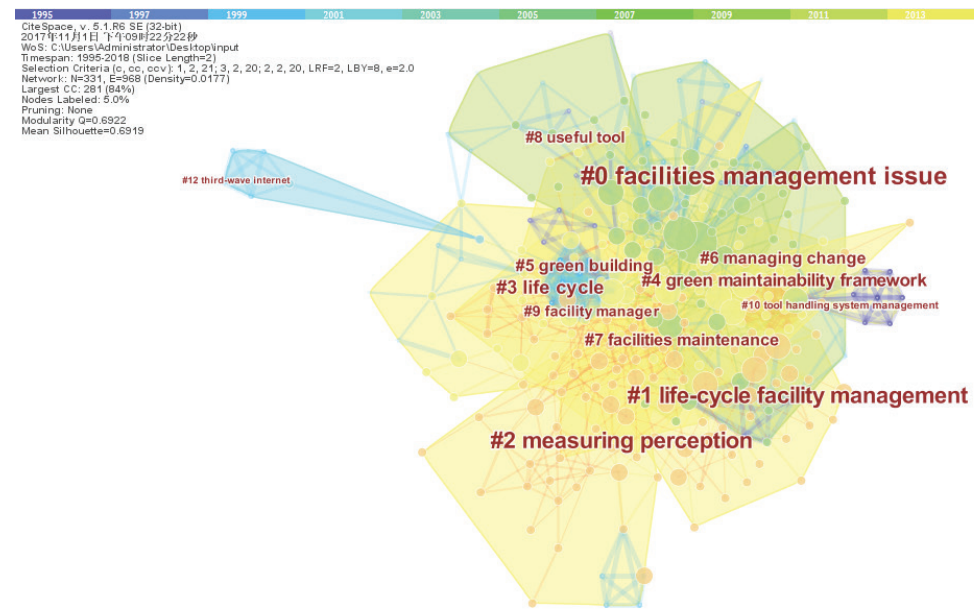

Figure 4. Cluster analysis in the FM field: 1995-2018 
\& Sandanayake, 2017), and early involvement of facility mangers into project management team is a great value adding activity for the optimization of the life-cycle building performance (Shah, 2008). "Measuring perception (\#2)" is related to strategic performance management in FM, referring to users' observations, opinions, and awareness of both their environment and the service received (Tucker \& Smith, 2008). "Green maintainability framework (\#4)", and "Green building (\#5)" are within the scope of sustainable FM to incorporate sustainable development principles in buildings and the built environment as an ultimate FM goal (Komurlu, Arditi, \& Gurgun, 2014). Last but not least, as FM is generally considered "integrated management of the workplace to enhance the performance of the organization" (Mudrak, Van Wagenberg, \& Wubben, 2004), "Facilities management issue (\#0)" and "Facilities maintenance (\#7)" are interrelated and interacted in the FM practice that deals the diversities of facilities, organizations, business sectors, the surrounding environment, and context and circumstance (Cairns, 2003; Chotipanich, 2004; Tucker, Masuri, \& Cotgrave, 2017). Each of the six abovementioned areas, namely changing circumstances, growing information technology, all-round facility manager, strategic performance management, sustainable $F M$, and $F M$ practice, are further discussed in this section.

\subsection{Changing circumstances: opportunities and challenges}

FM is an emerging sector driven by the needs of social and economic development, and its development fluctuates with the prosperity and decline of the organizational external circumstances. Some significant changes have taken place over the past few years, and these changes track the development of FM from different perspectives (Siitonen, Tuomaala, Suominen, \& Ahtila, 2010). Indeed, changes are not in isolation, having integrated effects on FM and bring both opportunities and challenges. Meng (2015) believed that increased use of outsourcing, moving from operational to strategic level, early involvement of FM in design, and the culture of innovation are major opportunities for FM development. For example, outsourcing has become prevalent with the rapid development in the FM sector, meaning that more and more organizations would outsource their non-core business activities to external specialists who can provide effective and efficient services, particularly in the areas of cleaning, catering, security, and maintenance (Ikediashi \& Odesola, 2016). Organizations can hire a team of professional FM consultants or form a partner team. In addition, other changes have also provided good development opportunities for FM, for example, the pressure of investment returns and operating costs, deepening the reform of the operational management system driven by innovation, the urgent need for a green and personalized working environment, and the requirements for business continuity management.

Certainly, challenges come together with opportunities facing changes. Preparing for potential changes and responding quickly and effectively to existing changes is a challenge for FM. For example, how to adapt to environmental changes (e.g. climate change and extreme events). However, very few organizations conduct detailed risk assessments in current practices, not to mention the development of integrated disaster management plans that address the environmental challenges. Therefore, it is critical for FM organizations to develop feasible and adaptive solutions for potential environmental threats. Due to the expansion of the market and competition, the internationalization of the geographical distribution of organizations has brought about differences in culture, language, laws, systems, standards and educational backgrounds among national teams. Thus, organizations should also focus on strategies that provide seamless workflows to address these differences. In addition, the continuous emergence of novel management innovation schemes, such as strategic management models and investment and financing models, is also a challenge that FM organizations face. Outsourcing strategy and Public-Private Partnership (PPP) may bring changes in working patterns, organizational culture, and management styles, as well as perturb organizational activities (Hashim, Sapri, \& Low, 2016). Therefore, we need to conduct more targeted research and practice to guide change management.

\subsection{Enhancing information technology: efficiency and value added}

Information is critically important for supporting efficient and effective building maintenance and day-to-day operations. However, the FM sector continues to struggle with information management. Stakeholders waste a huge amount of money looking for, validating, and/or recreating facility information that should be readily available (Gallaher, O'Connor, Dettbarn, Jr., \& Gilday, 2004). Part of reason is the peculiarity and fragmentation of information available (Kim et al., 2018), and the additional reason is that advanced information technology is lagging or inadequately applied in FM. Most importantly, the concept and strategy of "data-driven FM" need to be promoted and studied.

The increasing needs of customers and the advances in science and technology have facilitated the use of new technologies and tools in FM, such as BIM, RFID, cloud computing, IoT, image recognition, virtual reality, big data analytics, Integrated Workplace Management System (IWMS), and so on (Wong et al., 2018). Among those, BIM has received special attention by contributing to a sophisticated FM system that streamlines operation and maintenance over long-term using 3D geometry and attribute (Kelly, Serginson, Lockley, Dawood, \& Kassem, 2013; Gurevich, Sacks, \& Shrestha, 2017). However, the application level of BIM in FM is still limited and unsatisfactory (Dixit, Venkatraj, Ostadalimakhmalbaf, Pariafsai, \& Lavy, 2019). The application of BIM technology is concentrated in the project design and construction phase. Some models are often left unused or useless after the construction is completed. There are many reasons for 
this, lack of the awareness of BIM-FM integration benefit, lack of interoperability between FM and BIM authoring tools, lack of clearly defined FM data requirements, lack of guiding norms and compliance requirements for the application of BIM in FM, lack of systematic staff matching strategies, lack of clear stakeholder accountability rules, and lack of mature market operating mechanisms and business models, etc. In addition, it is necessary to establish the concept that BIM application should start from FM. Future studies are needed to review and improve the BIM open standards and data specifications to satisfy actual data and information required for FM.

New technologies and tools transform the FM industry towards refinement, standardization, and digitalization, and create an efficient working environment. In this increasingly data-driven business environment, FM organizations nowadays can use emerging technologies to capture realtime data and make more intelligent predictions and decisions, and facility managers can interact with visualization techniques on a regular basis for various purposes such as facility maintenance, occupant comfort, equipment monitoring, safety and security. The FM industry and enterprises should strengthen their understanding and attention to data, improve their ability to process and use data. They also should deploy data strategic objectives, theoretical systems, and application models to make data the core competitiveness and innovative driving force of FM services.

\subsection{All-round facility manager: excellent ability and life-cycle participation}

FM emerged as a result of the integration of three main strands of activities, i.e. property management, property operations and maintenance, and office administration. However, they have quite different financial impacts and skill requirements. Although there is a lack of clarity regarding the nature, status, image, and identity of FM within organizations, facility managers are in charge of multiple services within the organizations, and with a coherent set of information, skills, and practices (Drion, Melissen, \& Wood, 2012). The level of professional skills and quality of facility managers are indicators for measuring the management level of organizational facilities, and also are the primary factors affecting the success or failure of FM. The transformation of science and technologies and the emergence of new business demands nowadays have raised many challenges to the facility managers.

New skills and required expertise in FM are completely different from the existing practice (Pilanawithana \& Sandanayake, 2017). Novel materials, high-tech products, and innovative systems are advancing our built environment in a rapid fashion. The adoption of automation would create new processes for FM activities to replace existing process. A large amount of data from device sensors will be the key element for decision making and cost reduction. These changes require facility managers to quickly adapt to novel technology and methods to manage future facilities. In addition to technical skills, facility managers must have a stra- tegic vision and an ability to make comprehensive decisions and judgments. They should be able to identify clear dominant directions, basic ideas, technical routes, and organizational approaches in the process of discovering, analysing, and resolving facility management issues. Abilities such as skills of efficient relationship management, communication, collaboration, and problem-solving accomplishment allow facility managers to accurately communicate their strategic value to the senior managers.

Due to the job nature of traditional FM that only include services on cleaning, repairing, and maintenance, FM has very limited interaction with engineering, architecture, and other related professionals, until recently, people are increasingly aware of the importance of facility managers involved in design and construction. At the design phase, facility managers can help reduce procurement costs by offering facilities suggestions that better suit organizational/individual needs and help create an environment to facilitate the operation, maintenance and management of facilities. For example, for the integration of BIM and FM, facility managers could even actually help set up a FM data transfer template to define the type, format and attribute of data to be retained and added during the construction and handover stages of BIM (Dixit et al., 2019). At the construction phase, facility managers can help ensure data consistency from construction to operation, rapid commissioning of the building, and effective communication between all relevant parties throughout the life-cycle. Understanding the role of facility managers at different stages of a project life-cycle as well as developing organizational and work models that enable facility managers to participate in design and construction phases are worth exploring in future research. Moreover, facility managers need to promote the close relationship between FM and the overall strategy of the organization. Thus, the senior managers of organizations should be aware of the significance and importance of FM in supporting organizational strategy and core business development, and they should help facility managers increasingly participate in the organizational strategic decision-making process.

\subsection{Strategic performance management: user- centric and benchmarking}

During the competitive development of FM, two aspects of FM practice, hard and soft, have evolved (Sullivan, Georgoulis, \& Lines, 2010; Steenhuizen, Flores-Colen, Reitsma, \& Ló, 2014). Hard practice refers to engineering-based practices, while soft practice relates to hospitality and service operations. This split manifests itself in management structures, outsourced FM contracts, and organizational departments and teams (Roper \& Payant, 2014). Realizing the imbalance between hard and soft FM research, a FM institution in the UK recently have encouraged FM researchers to conduct more soft services-related research (Nenonen \& Sarasoja, 2014). End-users may have a significant impact on FM services, both unpredictable and costly. Therefore, the concept of user-centric should 
guide FM development and services. Most importantly, customer relationship management should be the focus of FM practices and research. Continuously improve customer satisfaction and loyalty by providing customers with personalized FM services and establishing long-term and stable relationships with customers.

Performance measurement is a process of setting key drivers in order to assess, evaluate, and/or change core business objectives (Koleoso, Omirin, Adewunmi, \& Babawale, 2013). It is an indispensable process for effectively implementing continuous improvement and value addition in business (Lai \& Man, 2017). Customer perception has been identified as a key attribute for performance measurement. Tucker and Smith (2008) researched on users' perceptions within an organizational context of FM, strengthened the importance of users on performance measurement. Tucker and Pitt (2009) also tested and validated customer performance measurement metrics through the conceptual model developed. In addition, benchmarking has always been an important topic in the FM field as it is a rational way to ensure that the organization meets customer needs. The benchmarking process in FM serves the purpose of comparing with peers and best practices to achieve improved performance (Ho, Chan, Wong, \& Chan, 2000). However, most facility managers and staffs are still concerned with data when conducting benchmarking, rather than considering how to integrate best practices into the benchmarking system. With the advent of more cloud-based FM applications, source data for all facility management benchmarks can be accessed from the Internet, making data inheritance and processing easier, saving time and reducing human error. In future practice and research, we should pay more attention to the application of social media in benchmarking.

\subsection{Sustainable FM: strategy and tactics}

To date, the building sector has been a major source of energy consumption and global greenhouse gas emissions. It is estimated that in Europe and USA, $80 \%$ of the climate change impact by buildings is generated during the operation phase in Europe and USA (Junnila, 2007). FM is considered to promote the sustainable development of the built environment, and sustainability may be an important value-added service in the FM field. Facility managers are also expected to be the powerful enablers of sustainable practices. Sustainability management of facilities will ultimately benefit organizations by increasing financial returns, increasing productivity and reducing the harmful effects on the environment (Bortolini \& Forcada, 2018). Actually, sustainable facilities management (SFM) has been selected as one of the primary research themes in the EuroFM network (Andersen, Rasmussen, \& Jensen, 2012; Junghans \& Olsson, 2014). Current research on SFM mainly focuses on building performance (e.g. life-cycle assessment and $\mathrm{CO}_{2}$ emissions) (Ucar, Inalli, \& Balo, 2011), sustainable building materials (Singhaputtangkul, Pheng Low, \& Lin Teo, 2011), sustainable tools and standards (e.g., indicators and certifications)
(Peng Xu, Chan, \& Qian, 2012), building design and sustainability (Renukappa, Egbu, Akintoye, \& Goulding, 2012), the management of sustainability in the built environment (Gunatilake \& Perera, 2018), and green buildings (Balaban \& de Oliveira, 2017).

However, in general, current SFM research remains insufficient and isolated, and there is some limitation. The research data in most studies is only derived from one country or even one case study of a project. At the same time, there is a lack of longitudinal studies that conduct in-depth studies of the long-term effects of interventions. In practice, majority of the facility teams do not practice sustainability services in FM due to lack of awareness and technology. So, in the future, more research is needed to gain a deeper understanding of sustainability in FM, focusing on, for example, how to document and measure the environmental, social and economic impacts of building operations? How to integrate sustainability into FM at the strategic, tactical and operational levels? What are the barriers to implementing sustainable services for the facility teams? What technologies can help achieve sustainable transformation at the organizational, architectural and social levels, and what are their positive and negative impacts?

\subsection{Innovative FM practice: research-practice transformation and standardization}

From the early stages of FM to the current stage of integration and standardization, the academics in the FM field has generated valuable outcomes. The maturity level of current FM research indicates that it is time to associated research findings with engineering practice. This process of association and transformation is not ideal, especially the application of research results in FM practice. According to Chotipanich (2004), facility professionals have not learned enough from the research and applied innovations. On the one hand, there are few literatures on the topic of translating FM research into the practice. On the other hand, the difficulty of putting research results into practice is universal. The issue is not as simple as producing research results with the belief that they will be used in practice. Exploring the potential strategies and approaches to bridge the gap between FM research and practice is an important direction of future efforts. For example, encouraging practice-oriented research, and encouraging practitioners to participate in the entire process of research (identification, conceptualization, implementation, evaluation, synthesis, and communication of information). Advancement in FM field requires the combined efforts of practitioners and researchers.

Standardized FM practice has become a trend, and it can be achieved through shared practices, research, innovation, best practices, and global metrics (Roper, 2017). FM professional associations also can contribute by ensuring the spread of innovation to their members. At the same time, the standardization of the FM industry can improve the performance, status and recognition of facility professionals to a certain extent. 


\section{Conclusions}

Over the last decades, FM has been considered a key element in managing organizational resources, services and the working environment, providing short-term and longterm support for the organization's core business. The value of FM mainly includes: (1) providing and maintaining a high-quality workspace; (2) reducing the life cycle operating costs; (3) supporting the organizational development strategy and core business; and (4) ensuring business continuity under emergencies.

Along with the societal, political, and economic changes, FM is evolving with new opportunities and challenges. The increasing use of outsourcing, shifting from operational level to strategic level, the early involvement in the design and construction phases, the culture of innovation are considered to be major opportunities for FM development. At the same time, the pressure of investment returns and operating costs, the reform of operational management systems, the urgent need for a green and personalized working environment, and the requirements for business continuity management are parts of the source of opportunities for FM development. Meanwhile, globalization, emergence of novel management innovation schemes, and environmental changes, both climate change at the global scale and new working environment, pose challenges for FM.

Information is critical for supporting efficient and effective building maintenance and day-to-day operations. As a strategic concept of the organizations, computer-aided FM is becoming an indispensable technology for successful implementation of FM. The potential benefits of BIM-FM integration also draw attention and agreement. However, there are many practice and research needs to be done to expand the benefits. Capturing buildings' intricate and expanding FM data can be very difficult, and requires strong strategic and tactical skills for facility managers. They must keep learning and stay up to date. There is also a trend for facility mangers to involve in early design and construction phases.

Building facilities and services must be user-centric because users have a significant impact on FM services. Measuring user performance can effectively help achieve business goals. Sustainable facilities management has been identified as one of the emerging themes in the future of FM research and effective SFM practices will provide enormous benefits to the environment and contribute to sustainability. How to transform theoretical findings into practical applications is the next steps of FM development.

It is worth mentioning that, there is a dilemma in the current research on FM - the lack of substantive innovative research achievement ${ }^{1}$. The main reasons may be the lack of close connection between practices and research, and the FM industry lacks comprehensive staffs who are

1 The authors thank an anonymous reviewer for suggesting this point. familiar with FM practices and have the ability to conduct scientific research. Another worse reason may be that some publications were written by researchers/students only based on existing publications. These reasons may also lead to such a phenomenon that in some areas there is rare FM practice, but there are many publications focusing on FM in the region. More rigorous and valuable research deserves to be promoted.

This study contributes to the development of the FM field in three ways. First, it helps understand the development, evolution and current status of FM research priorities holistically by carefully examining and analysing the FM studies from 1995 to 2018. Second, the emerging FM research trends scattered in existing research are summarized and deepened to provide insightful information so that academics must take into consideration to improve the validity and reliability in their future research. Last but not least, the research findings will assist and guide FM practitioners to address future opportunities and challenges.

\section{Acknowledgements}

This material is based in part upon work supported by the National Natural Science Foundation of China under Grant Nos 71471136 and 71390523, by Shanghai Pujiang Talent Program under Grant No. 17PJC101, and by Shanghai Chenguang Talent Program under Grant No. 18CG21. Any opinions, findings, and conclusions or recommendations expressed in this material are those of the authors and do not necessarily reflect the views of the funding agencies.

\section{References}

Ahmed, V., Tezel, A., Aziz, Z., \& Sibley, M. (2017). The future of Big Data in facilities management: opportunities and challenges. Facilities, 35(13-14), 725-745.

https://doi.org/10.1108/F-06-2016-0064

Andersen, P. D., Rasmussen, B., \& Jensen, P. A. (2012). Future trends and challenges for FM in the Nordic countries. In Facilities management research in the Nordic countries: Past, present and future. Polyteknisk Boghandel og Forlag.

Aziz, N. D., Nawawi, A. H., \& Ariff, N. R. M. (2016). ICT evolution in Facilities Management (FM): Building Information Modelling (BIM) as the latest technology. Procedia - Social and Behavioral Sciences, 234, 363-371. https://doi.org/10.1016/j.sbspro.2016.10.253

Balaban, O., \& de Oliveira, J. A. P. (2017). Sustainable buildings for healthier cities: assessing the co-benefits of green buildings in Japan. Journal of Cleaner Production, 163, S68-S78. https://doi.org/10.1016/j.jclepro.2016.01.086

Bortolini, R., \& Forcada, N. (2018). Facility managers' perceptions on building performance assessment. Frontiers of Engineering Management, 5(3), 324-333. https://doi.org/10.15302/J-FEM-2018010

Cairns, G. (2003). Seeking a facilities management philosophy for the changing workplace. Facilities, 21, 95-105.

https://doi.org/10.1108/02632770310476705 
Chen, C. (2006). CiteSpace II: detecting and visualizing emerging trends and transient patterns in scientific literature. Journal of the American Society for Information Science and Technology, 57(3), 359-377. https://doi.org/10.1002/asi.20317

Chen, C. (2014). The CiteSpace manual. College of Computing and Informatics.

Chen, H., Zhao, G., \& Xu, N. (2012). The analysis of research hotspots and fronts of knowledge visualization based on CiteSpace II. In International Conference on Hybrid Learning (pp. 57-68). Springer. https://doi.org/10.1007/978-3-642-32018-7_6

Chotipanich, S. (2004). Positioning facility management. Facilities, 22, 364-372. https://doi.org/10.1108/02632770410563086

Dixit, M. K., Venkatraj, V., Ostadalimakhmalbaf, M., Pariafsai, F., \& Lavy, S. (2019). Integration of facility management and building information modeling (BIM): a review of key issues and challenges. Facilities, 37(7/8), 455-483.

https://doi.org/10.1108/f-03-2018-0043

Drion, B., Melissen, F., \& Wood, R. (2012). Facilities management: lost, or regained? Facilities, 30(5-6), 254-261. https://doi.org/10.1108/02632771211208512

Ebbesen, P., \& Bonke, S. (2014). Identifying concepts for studying implementation of information technology in facilities management. In P. A. Jensen (Ed.), Proceedings of CIB Facilities Management Conference 2014 (pp. 417-429). Polyteknisk Boghandel og Forlag.

Enoma, A., \& Allen, S. (2007). Developing key performance indicators for airport safety and security. Facilities, 25(7-8), 296315. https://doi.org/10.1108/02632770710753334

Gallaher, M. P., O'Connor, A. C., Dettbarn, Jr., J. L., \& Gilday, L. T. (2004). Cost analysis of inadequate interoperability in the U.S. capital facilities industry. National Institute of Standards \& Technology. https://doi.org/10.6028/NIST.GCR.04-867

Gunatilake, S., \& Perera, B. (2018). Built environment sustainability: what's new and what's next? Built Environment Project and Asset Management, 8(5), 430-433.

https://doi.org/10.1108/BEPAM-11-2018-135

Gurevich, U., Sacks, R., \& Shrestha, P. (2017). BIM adoption by public facility agencies: impacts on occupant value. Building Research and Information, 45(6), 610-630. https://doi.org/10.1080/09613218.2017.1289029

Hashim, H. A., Sapri, M., \& Low, S. T. (2016). Public private partnership (PPP) facilities management for healthcare services in Malaysia: the challenges of implementation. Journal of Facilities Management, 14(4), 350-362. https://doi.org/10.1108/JFM-02-2016-0005

Ho, D. C. W., Chan, E. H. W., Wong, N. Y., \& Chan, M. W. (2000). Significant metrics for facilities management benchmarking in the Asia Pacific region. Facilities, 18, 545-556. https://doi.org/10.1108/02632770010358088

Hossain, M. M., Prybutok, V., \& Evangelopoulos, N. (2011). Causal Latent Semantic Analysis (cLSA): an illustration. International Business Research, 4(2), 38-50. https://doi.org/10.5539/ibr.v4n2p38

Ikediashi, D. I., \& Odesola, I. A. (2016). Facilities management outsourcing: theoretical trends and evidence from practice in Nigeria and United Kingdom. International Journal of Strategic Property Management, 20(2), 207-219. https://doi.org/10.3846/1648715x.2015.1132789

Jordani, D. A. (2010). BIM and FM: the portal to lifecycle facility management. Journal of Building Information Modeling, 13, 16.

Junghans, A., \& Olsson, N. O. E. (2014). Discussion of facilities management as an academic discipline. Facilities, 32(1-2), 6779. https://doi.org/10.1108/F-10-2012-0078
Junnila, S. (2007). The potential effect of end-users on energy conservation in office buildings. Facilities, 25(7-8), 329-339. https://doi.org/10.1108/02632770710753352

Kaufman, L., \& Rousseeuw, P. J. (2009). Finding groups in data: an introduction to cluster analysis (Vol. 344). John Wiley \& Sons.

Kelly, G., Serginson, M., Lockley, S., Dawood, N., \& Kassem, M. (2013). BIM for facility management: a review and a case study investigating the value and challenges. Paper presented at 13th International Conference on Construction Applications of Virtual Reality, London, United Kingdom.

Kim, K., Kim, H., Kim, W., Kim, C., Kim, J., \& Yu, J. (2018). Integration of IFC objects and facility management work information using Semantic Web. Automation in Construction, 87, 173-187. https://doi.org/10.1016/j.autcon.2017.12.019

Koleoso, H., Omirin, M., Adewunmi, Y., \& Babawale, G. (2013). Applicability of existing performance evaluation tools and concepts to the Nigerian facilities management practice. International Journal of Strategic Property Management, 17(4), 361-376. https://doi.org/10.3846/1648715x.2013.861367

Komurlu, R., Arditi, D., \& Gurgun, A. P. (2014). Applicability of LEED's energy and atmosphere category in three developing countries. Energy and Buildings, 84, 690-697. https://doi.org/10.1016/j.enbuild.2014.07.095

Lai, J. H. K., \& Man, C. S. (2017). Developing a performance evaluation scheme for engineering facilities in commercial buildings: state-of-the-art review. International Journal of Strategic Property Management, 21(1), 41-57. https://doi.org/10.3846/1648715X.2016.1247304

Lavikka, R. H., Lehtinen, T., \& Hall, D. (2017). Co-creating digital services with and for facilities management. Facilities, 35(9-10), 543-556. https://doi.org/10.1108/F-12-2016-0101

Li, J., \& Chen, C. (2016). Citespace: text mining and visualization in scientific literature. Beijing, China: Capital University of Economics and Business Press.

Maliene, V., Alexander, K., \& Lepkova, N. (2008). Facilities management development in Europe. International Journal of Environment and Pollution, 35(2/3/4), 171-184.

https://doi.org/10.1504/ijep.2008.021354

Meng, X. (2015). Facilities management: tracing its development trajectory. Property Management, 33(3), 212-223.

https://doi.org/10.1108/PM-12-2013-0059

Mignard, C., \& Nicolle, C. (2014). Merging BIM and GIS using ontologies application to urban facility management in ACTIVe3D. Computers in Industry, 65(9), 1276-1290. https://doi.org/10.1016/j.compind.2014.07.008

Mudrak, T., Van Wagenberg, A., \& Wubben, E. (2004). Assessing the innovative ability of FM teams: a review. Facilities, 22, 290-295. https://doi.org/10.1108/02632770410561286

Nenonen, S., \& Sarasoja, A. L. (2014). Facilities management research in Finland - state-of-art about current Finnish PhDprojects. Facilities, 32(1-2), 58-66. https://doi.org/10.1108/F-10-2012-0079

Newman, M. E. J. (2006). Modularity and community structure in networks. Proceedings of the National Academy of Sciences, 103(23), 8577-8582. https://doi.org/10.1073/pnas.0601602103

Nielsen, S. B., Sarasoja, A. L., \& Galamba, K. R. (2016). Sustainability in facilities management: an overview of current research. Facilities, 34(9/10), 535-563. https://doi.org/10.1108/F-07-2014-0060

Pärn, E. A., Edwards, D. J., \& Sing, M. C. P. (2017). The building information modelling trajectory in facilities management: a review. Automation in Construction, 75, 45-55. https://doi.org/10.1016/j.autcon.2016.12.003 
Parsanezhad, P., \& Dimyadi, J. (2014). Effective facility management and operations via a BIM-based integrated information system. In Proceedings of CIB facilities management conference using facilities in an open world creating value for all stakeholders, Copenhagen, 21-23 May 2014 (pp. 442-453). Polyteknisk Boghandel og Forlag.

Peng Xu, P., Chan, E. H. W., \& Qian, Q. K. (2012). Key performance indicators (KPI) for the sustainability of building energy efficiency retrofit (BEER) in hotel buildings in China. Facilities, 30(9/10), 432-448. https://doi.org/10.1108/02632771211235242

Pilanawithana, N. M., \& Sandanayake, Y. G. (2017). Positioning the facilities manager's role throughout the building lifecycle. Journal of Facilities Management, 15(4), 376-392. https://doi.org/10.1108/JFM-06-2016-0024

Pollack, J., \& Adler, D. (2015). Emergent trends and passing fads in project management research: a scientometric analysis of changes in the field. International Journal of Project Management, 33(1), 236-248. https://doi.org/10.1016/j.ijproman.2014.04.011

Renukappa, S., Egbu, C., Akintoye, A., \& Goulding, J. (2012). A critical reflection on sustainability within the UK industrial sectors. Construction Innovation, 12(3), 317-334. https://doi.org/10.1108/14714171211244578

Roper, K. O. (2017). Facility management maturity and research. Journal of Facilities Management, 15(3), 235-243. https://doi.org/10.1108/JFM-04-2016-0011

Roper, K., \& Payant, R. (2014). The facility management handbook. Amacom. https://doi.org/10.1002/9781118771686.ch1

Rundell, R. (2006). 1-2-3 Revit: BIM and FM, How can BIM benefit facilities management. AIA Cadalyst. Retrieved from https://www.cadalyst.com/cad/building-design/1-2-3-revitbim-and-fm-3432

Shah, S. (2008). Sustainable practice for the facilities manager. John Wiley \& Sons. https://doi.org/10.1002/9780470759677

Shohet, I. M., \& Lavy, S. (2004). Healthcare facilities management: state of the art review. Facilities, 22, 210-220. https://doi.org/10.1108/02632770410547570

Shohet, I. M., \& Lavy, S. (2017). Facility maintenance and management: a health care case study. International Journal of Strategic Property Management, 21(2), 170-182. https://doi.org/10.3846/1648715X.2016.1258374

Siitonen, S., Tuomaala, M., Suominen, M., \& Ahtila, P. (2010). Implications of process energy efficiency improvements for primary energy consumption and $\mathrm{CO}_{2}$ emissions at the national level. Applied Energy, 87(9), 2928-2937.

https://doi.org/10.1016/j.apenergy.2009.09.024

Singhaputtangkul, N., Pheng Low, S., \& Lin Teo, A. (2011). Integrating sustainability and buildability requirements in building envelopes. Facilities, 29(5/6), 255-267.

https://doi.org/10.1108/02632771111120556

Steenhuizen, D., Flores-Colen, I., Reitsma, A. G., \& Ló, P. B. (2014). The road to facility management. Facilities, 32(1-2), 46-57. https://doi.org/10.1108/F-09-2012-0072

Sullivan, K., Georgoulis, S. W., \& Lines, B. (2010). Empirical study of the current United States facilities management profession. Journal of Facilities Management, 8(2), 91-103. https://doi.org/10.1108/14725961011041143

Tucker, M. P., Masuri, M. R. A., \& Cotgrave, A. (2017). Critical strategic issues for the integration of facilities management into the development process. Property Management, 35(4), 380-393. https://doi.org/10.1108/PM-05-2016-0022

Tucker, M., \& Pitt, M. (2009). Customer performance measurement in facilities management. International Journal of Productivity and Performance Management, 58(5), 407-422. https://doi.org/10.1108/17410400910965698

Tucker, M., \& Smith, A. (2008). User perceptions in workplace productivity and strategic FM delivery. Facilities, 26(5-6), 196-212. https://doi.org/10.1108/02632770810864989

Ucar, A., Inalli, M., \& Balo, F. (2011). Application of three different methods for determination of optimum insulation thickness in external walls. Environmental Progress and Sustainable Energy, 30(4), 709-719. https://doi.org/10.1002/ep.10531

Ventovuori, T., Lehtonen, T., Salonen, A., \& Nenonen, S. (2007). A review and classification of academic research in facilities management. Facilities, 25(5/6), 227-237. https://doi.org/10.1108/02632770710742192

White, A. D., Moseki, L. K., Tembo, E., \& Cloete, C. E. (2011). The principles and practice of facilities maintenance in Botswana. Journal of Corporate Real Estate, 13(1), 48-63. https://doi.org/10.1108/14630011111120341

Wong, J. K. W., Ge, J., \& He, S. X. (2018). Digitisation in facilities management: a literature review and future research directions. Automation in Construction, 92, 312-326. https://doi.org/10.1016/j.autcon.2018.04.006

Yalcinkaya, M., \& Singh, V. (2015). Patterns and trends in Building Information Modeling (BIM) research: a latent semantic analysis. Automation in Construction, 59, 68-80. https://doi.org/10.1016/j.autcon.2015.07.012 